\title{
Using Dynamic Geometry Software for the Intersection Surfaces
}

\author{
Timur Koparan ${ }^{1}$, Gül Kaleli Yılmaz ${ }^{2}$ \\ ${ }^{1}$ Ereğli Faculty of Education, Bülent Ecevit University, Zonguldak, Turkey. \\ ${ }^{2}$ Bayburt Faculty of Education, Bayburt University, Bayburt, Turkey \\ Correspondence: Timur Koparan, Ereğli Faculty of Education, Bülent Ecevit University, Zonguldak, Turkey
}

Received: July 10, 2015 Accepted: July 30, 2015 Online Published: August 7, 2015

doi:10.11114/jets.v3i5.939

URL: http://dx.doi.org/10.11114/jets.v3i5.939

\begin{abstract}
The purpose of this study is to define prospective teacher views about using dynamic geometry software for intersection surfaces. The study was conducted as a case study. For this purpose, data collection tool was developed based on the opinion of two experts. The data collection tool consists of 4 open-ended questions related to the intersection surfaces. The research sample consisted of 42 prospective mathematics teachers. Semi-structured interviews were conducted with three prospective teachers to obtain more detailed information. The analysis process was performed within a descriptive-interpretative approach to reveal the effects of dynamics geometry software on prospective teachers' opinion. Qualitative data was presented under various themes. The obtained data demonstrated that the prospective teachers had difficulties in determining the intersection surfaces, the intersections had been set incorrectly due to the incorrect drawings arising from the challenges in the visualization, and some conclusions had never gone beyond estimations. It was observed that the intersection surfaces were set easily in the learning environment supported by dynamic geometry software thanks to the visualization, cutting and moving features of the software. The obtained findings were supported by the snapshots of the prospective teachers' answers taken from the dynamic drawings and interview sections before using the software and then. The conclusion was reached that dynamic geometry software contributed more to the prospective teachers in the setting of intersection surfaces than the process in which pen and paper were used. As a result, the dynamics geometry software, especially in the teaching of surface intersection was found to be an effective tool.
\end{abstract}

Keywords: dynamic geometry software, geometry teaching, intersection surface, prospective teacher

\section{Introduction}

Developments in technology have made it mandatory to use the proper tools and equipment to the needs of the era in education. It is undoubted that computers have the leading place among these technologies. Because of the fact that the objects in real life are three-dimensional, and computers allow the visualization of three-dimensional objects, computers attracted more interest in education over the last twenty year. Nevertheless the students cannot be successful in developing strong conceptual understanding in geometry that is an important part of mathematics (Mistretta, 2000). It has been demonstrated in several studies that various difficulties are experienced in the realization of the gains related to the three-dimensional geometry which are in the curriculum (Kösa, 2011). The challenges arising from the interpretation of the static views of the geometric objects lie at the root of these difficulties (Accascina \& Rogora 2006; Kösa, 2011). Another difficulty arises when a three-dimensional shape is tried to be formed on a two-dimensional plane (Baki, Kösa, \& Karakuş, 2008). Gürbüz and Gülburnu (2013) suggested that a teaching planning should be done in which the students can experience, make conclusions and generalization to improve their spatial and three-dimensional visualization skills. Otherwise, they stated that it will continue the challenge in the emergence student's visual, aesthetic and intuitive sense. As it is known, the students who cannot find themselves in such a rich experience tend to memorize the rules, relationships, concepts and, when necessary, the proofs (Demir, 2010; Eryiğit, 2010; Özen, 2009). Therefore, studies are needed to create learning environments in which three-dimensional visualization and spatial skills can be improved.

Today, it is suggested that technology can be used effectively in the configuration of the learning environments in which students can learn the knowledge by experiencing and exploring. Kösa and Karakuş (2010) mention some structures both to reach the desired gains and achieve better conceptual learning in the geometry education, which are models, manipulatives, diagrams, three-dimensional dynamic geometry software that have been used recently. Güven and 
Karataş (2003) describe dynamic geometry software presented by the information technologies as promising tools to achieve conceptual learning. Dynamic geometry software is actually a type of computer software used to analyze the geometry topics. This software is an important teaching tool that transforms geometry in a dynamic model by moving the shapes and is used to rebuild the shapes. According to Baki (2000), this software that embodies the concepts and relationships by visualization effects the teaching and learning in a positive way when used effectively and appropriately. This software has enabled to make assumptions about geometric objects and establish relationships between geometric objects, for it makes geometry, which is the visual perception center of the mathematics, dynamic on the computer screens by rescuing it from the static structure of the process in which pen and paper are used. Cabri $3 \mathrm{D}$, which is a three-dimensional dynamic geometry software, has an important potential for the visualization of the geometric objects and conceiving three-dimension (Accascina \& Rogora, 2006). In Cabri 3D application, many structures (prisms, cylinders, pyramids, unit cubes, etc.) that cannot be seen, cannot be created (being complex) in the traditional environments (blackboard, etc.) or in the two-dimensional software, and need long time for being created, can easily be created in three-dimension, rotated, seen from different angles and their outer surfaces can be opened. Thus, the relationships between the structures that are formed similarly to the originals, features, generalization and calculation can easily be studied. In addition, the distinctive features of Cabri 3D software provide us with the opportunity to examine geometry topics dynamically that require three-dimensional spatial perception and depth.

In this study, we focused on prospective teachers views related to the intersection surfaces in the learning environment supported by the dynamic geometry software. It was observed how prospective teachers made conclusions by making experiments and observations using the moving particularly and cutting features of Cabri 3D software; the way of thinking in the learning environment supported by Cabri 3D was examined from various angles.

\section{Method}

Within this study, it was aimed to investigate prospective teacher' views about before and after using dynamic geometry software for intersection surfaces. In this study, case study approach was used. While collecting data for the research, semi-structured interview and open ended questions were used. These questions are shapeless questions. Some researchers suggest that teacher should use shapeless questions as far as shapely question and definition of geometric concepts (Karpuz, Koparan \& Güven, 2014).

\subsection{Participant}

This research was carried out in a higher education institution in Turkey in 2014-2015 academic year. The sample group consisted of 42 prospective mathematics teachers in Bülent Ecevit University. Of the participants, 25 were females and 17 were males. In addition, interviews were conducted with three prospective teachers. The prospective teachers who were purposefully selected from the prospective teachers by taking the success levels into consideration. The three success levels of these prospective teachers were low, medium and high.

\subsection{Implementation and Collection of Data}

In this study, an assessment questionnaire consisting of four open-ended questions, observations, and semi-structured interviews were used in order to determine the conclusions of the prospective teachers related to the intersections. The questions to be asked in the interviews were determined before the study. The study was conducted on the "Teaching Technologies and Material Development Course". Within the scope of this course, physical and abstract materials for mathematics and geometry topics are developed. The program of the activities performed in the course for three weeks is shown below.

Table 1 . The schedule of the course activities

\begin{tabular}{ll}
\hline Weeks & Course content \\
\hline 1st week & Learning about Cabri 3D, Manipulation (Manipulation, Redefinition) Points (Point, Intersection Point) \\
& Lines and Curves (Line, Segment, Ray, Circle, Arc, Conic, Intersection Curve) Surfaces (Plane, Polygon, \\
& Triangle, Half Plane, Sector, Cylinder, Cone, Sphere) \\
& Consructions (Perpendicular, Paralel, Bisector, Bisector Plane, Midpoint, Vector Sum, Cross producy, \\
& Measurement Transfer, Trajectory) \\
2nd week & Transformations (Central Symmetry, Half-Turn, Reflection, Translation, Rotation, Dilation, Inverse) \\
& Regular Polygons (Equilateral Triangle, Square, Regular Pentagon, Regular Hexagon, Regular Octagon, \\
& Regular Decagon, Regular Dodecagon, Pentagram) Polypedra (Tetrahedron, XYZ Box, Prism, Pyramid, \\
& Convex Polyhedron, Open Plyhedron) \\
3rd week & Regular Polyhedra (Regular Tetrahedron, Cube, Regular Octahedron, Regular Dodecahedron, Regular \\
& Icosahedron) Measurement and Calculation Tools Distance, Length, Aria, Volume, Angle, Dont Product, \\
& Coord \& Eduation(s), Calculator). Exercises (Estimating close states of the objects given as open in Cabri, \\
& Theorem of three perpendiculars) \\
\hline
\end{tabular}

The first author of this study is at the same time the teacher of this course. At the end of the pencil and paper process, 
the prospective teachers were introduced with Cabri 3D dynamic software. Because participants worked on threedimensional objects with Cabri 3D, they had the basic skills to be able to make constructions related to the open-ended questions asked.

At the beginning of the study, the prospective teachers answered the questions without using the dynamic software. Then they were given courses including Cabri 3D activities 4 hours per week for three weeks. The researcher was the teacher of the class during the application. At the end of the application, the same questions were asked again. The open-ended questions and interview questions prepared by the researchers were controlled by an expert as well. Participants are asked the following questions;

1. What will the intersection surface, which occurs when a full sphere is cut with a plane be like? Explain by drawing.

2. What will the intersection surface, which occurs when a vertical full cylinder is cut with a plane be like? Explain by drawing

3. What will the intersection surface, which occurs when a vertical full cone is cut with a plane be like? Explain by drawing

4. What will the intersection surface, which occurs when a full cube is cut with a plane be like? Explain by drawing

The participants were asked to answer the questions using a pen and paper at the first stage of the study and Cabri 3D dynamic geometry software at the end of the study.

\subsection{Data Analysis}

In this study, the prospective teachers' views were examined related to the intersection surfaces in a learning environment supported by dynamic geometry software. The findings were evaluated qualitatively. Basic data for the study are the qualitative data derived from the questions related to the plane and intersection of a sphere, vertical cylinder, vertical cone, and cube. The conclusions of the prospective teachers related to the intersection surfaces, the problems they experienced and reasons were tried to be demonstrated comparatively both in the dynamic environments and in the process in which pen and paper were used. In addition, interviews were conducted with prospective teachers. These interviews were recorded and transcribed. Themes were tried to be formed by examining these transcripts deeply. Then created themes were brought together and discussed.

\section{Results}

In this section, the answers of the prospective teachers to the open-ended questions in the data collection tool before and after using dynamic software were examined. The findings were supported by the answers of the prospective teachers to the questions and the solutions they did in Cabri 3D software. Results were presented as headings in question in the context of a data collection tool. In addition, the findings derived from the interviews were presented in order to reflect the opinions of the prospective teachers related to the activities in a more detailed way. These findings were supported by direct quotations from interviews and various themes.

\subsection{The Finding Obtained from the Intersection of Sphere and Plane}

Within the scope of the study, the prospective teachers were asked primarily "What will the intersection surface which occurs when a full sphere is cut with a plane be like? Explain by drawing." Before the application $76 \%$ of the prospective teachers gave the answer "circular region". When the answers were examined it was observed that some drawings had not been made at all while some others had been done but did not reflect the intersections. Therefore, it was determined that the prospective teachers had made predictions about the intersections. However, there were also other answers in which correct drawings but false explanations related to the intersection surfaces had been made. Figure 1 shows examples of answers before using software.
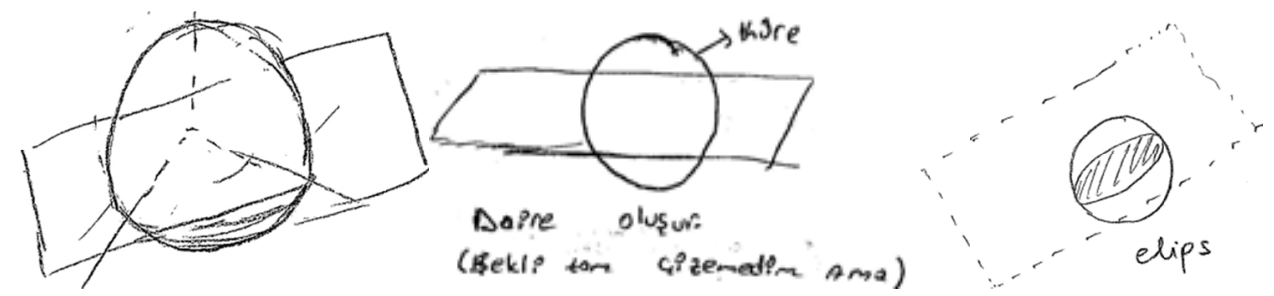

Figure 1. Examples of answers before using software related to the intersection of sphere and plane 
After using software, $98 \%$ of the prospective teachers gave the answer "circular region" to this question. It was observed that, using Cabri 3D, the prospective teachers had formed intersecting sphere and plane; then they had an idea about the intersection by looking at the top view by moving the shape. The examples of drawings of the prospective teachers after the application are presented in figure 2.

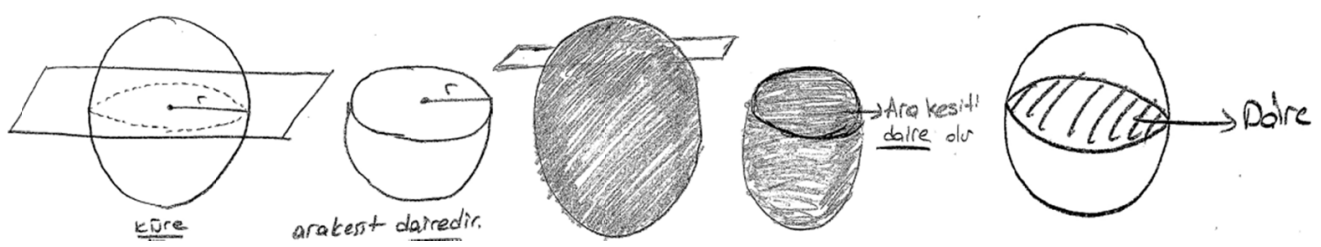

Figure 2. The examples of drawings for the intersection of sphere and plane after using software

As seen in Figure 2, the drawings made after the application were more realistic and understandable. Concerning the intersection surface, no answer was given apart from "circular region". This shows that the prospective teachers falling into error before using software did not make the same mistakes after using software. The experience of the prospective teachers with Cabri 3D affected their drawings and conclusions related to the intersection surfaces.

\subsection{The Findings Obtained from the Intersection of Vertical Cylinder and Plane}

In the study, the prospective teachers were asked the second question as "What will the intersection surface which occurs when a vertical full cylinder is cut with a plane, be like? Explain by drawing". The answers of the prospective teachers related to the intersection of vertical cylinder and plane before and after using dynamic software are presented in figure 3.

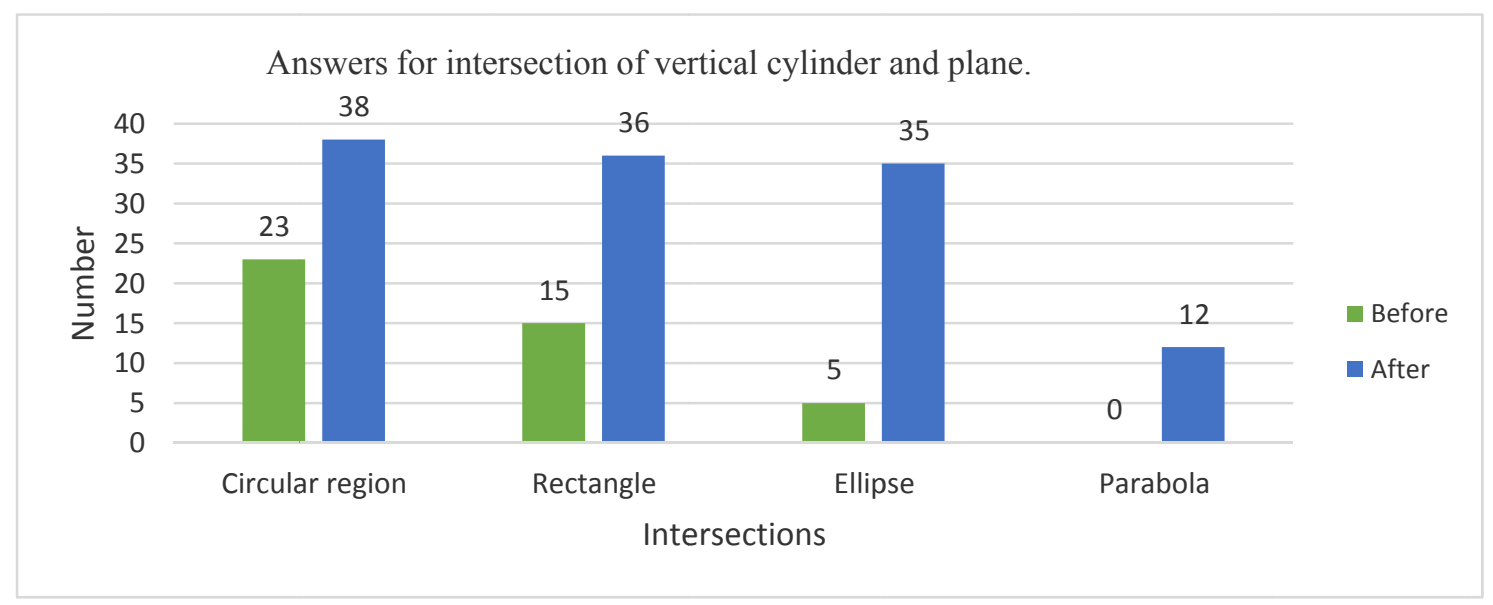

Figure 3. Answers for intersection of vertical cylinder and plane before using software and then.

As seen in Figure 3, about half of the prospective teachers gave "circular region" answer for the intersection of a vertical cylinder and plane before using the dynamic software. 15 prospective teachers gave "rectangle" and 5 gave "ellipse" answers. Some prospective teachers argued that the intersection would be a circular region in any case, no matter how the cylinder is cut by a plane. Some prospective teachers gave "circular region" answer for intersection although the cylinder was cut by a plane perpendicular to the cylinder and they drew it correctly. Sample answers about this situation are shown in Figure 4.

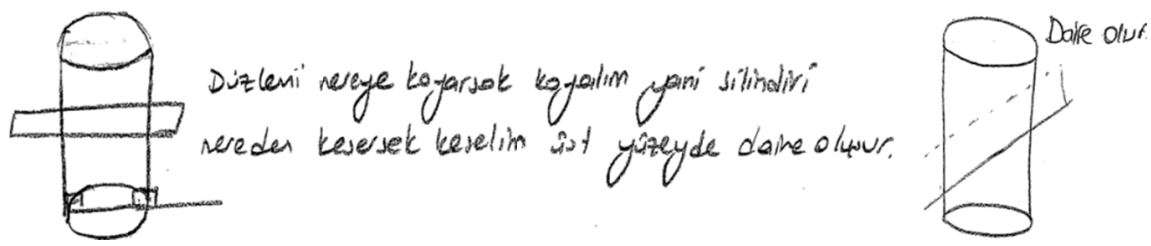

Figure 4. The examples of answers arguing that the intersection of vertical cylinder and plane are always a circular region.

Some prospective teachers misidentified the intersection, for they formed the shapes incorrectly. Incorrect answers were given for the intersection of solid vertical cylinder and plane such as circle, triangle, parallelogram, rectangles. Figure 5 shows examples of these wrong answers. 


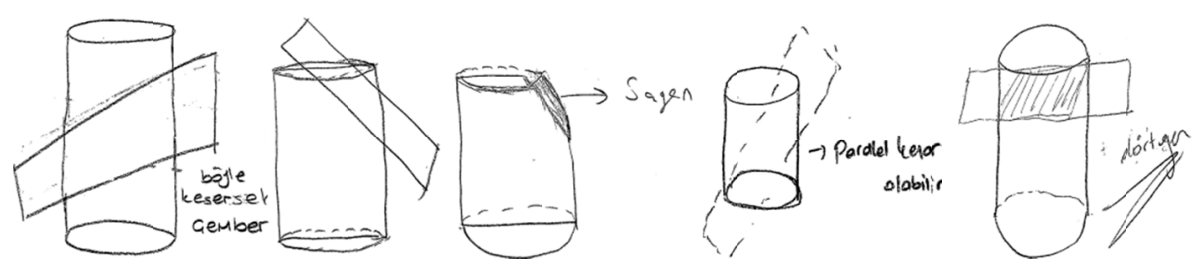

Figure 5. Examples of given answers for the intersection of vertical cylinder and plane after using software

As seen in Figure 5, the incorrect drawings made in two-dimensions led to false conclusions of the prospective teachers. In addition, it can be said that even if the drawings are made correctly, the intersections cannot be seen clearly. Therefore, the answers for the intersections did not go beyond predictions.

In the learning environment supported by Cabri 3D, the prospective teachers tried to identify the intersection surfaces by moving the shapes after they had drawn cylinder and plane. The drawings made by the prospective teachers are presented in Figure 6.
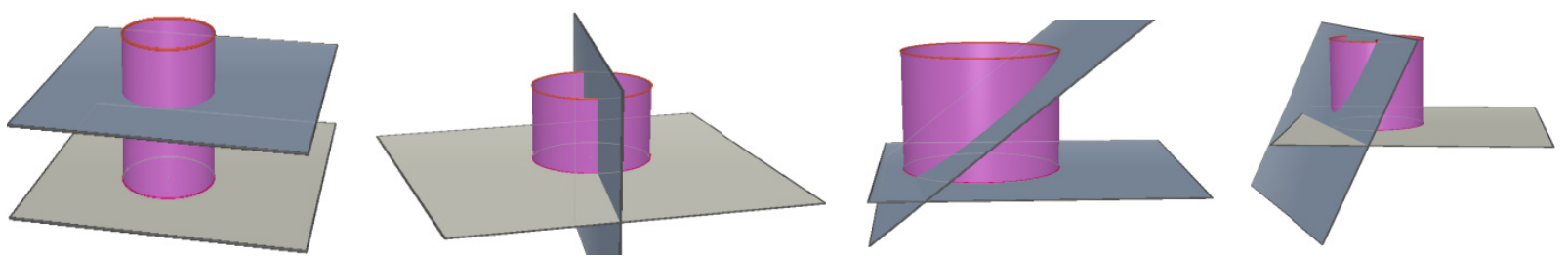

Figure 6. Examples of Cabri 3D drawings of the prospective teachers for the intersection of cylinder and plane.

None of the prospective teachers gave "parabola" answer for the intersection before the application but after doing activities with Cabri 3D, 12 prospective teachers gave "solid parabola" answer for the questions asking the intersection of vertical cylinder and plane. Figure 7 presents examples of the answers given after using software.
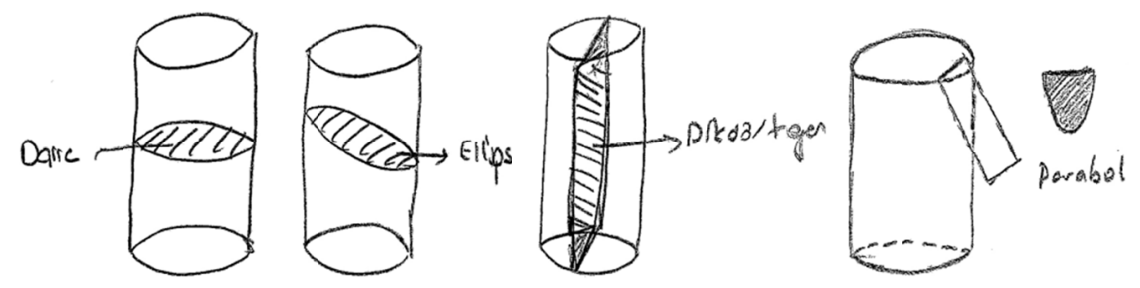

Figure 7. Examples of answers for the intersection of a vertical cylinder and a plane after using software

\subsection{The Findings Obtained From the Intersection of Vertical Cone and Plane}

The answers of the prospective teachers related to the intersection of vertical cone and plane before and after using dynamic software are presented in figure 8 .

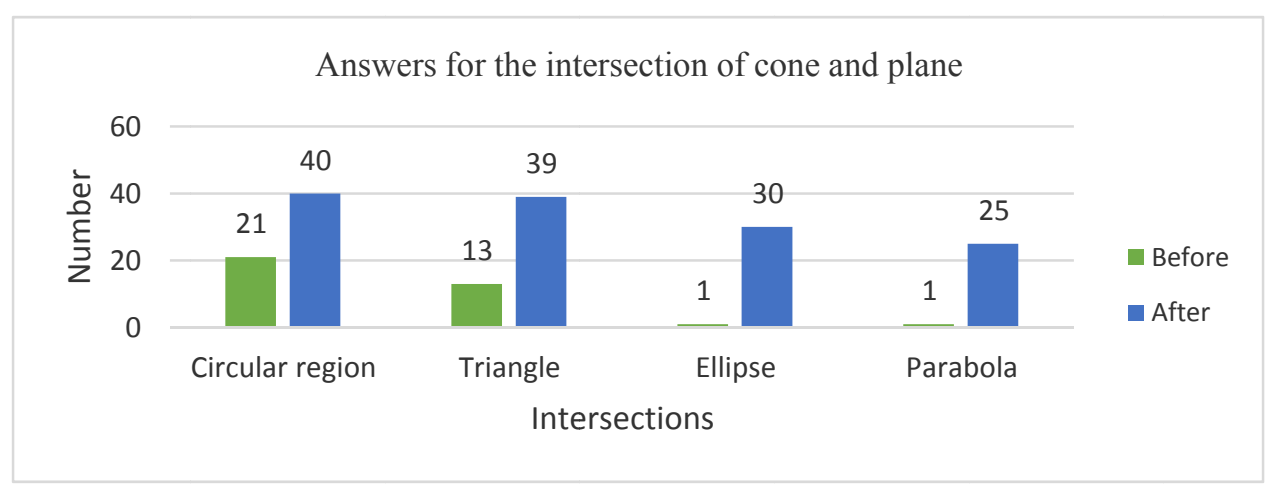

Figure 8. Answers for the intersection of vertical cone and plane before using software and then

As seen in Figure 8, half of the prospective teachers gave "circular region" answer for the intersection of vertical cone and plane before using the dynamic software. Only one student gave "ellipse" and one gave "parabola" answer while 13 prospective teachers gave "triangle" answer. It was observed that the prospective teachers had drawn the planes parallel to the cone base or perpendicular to the center of the cone base. This situation prevented them from seeing other intersections. Examples related to this situation are presented in Figure 9. 

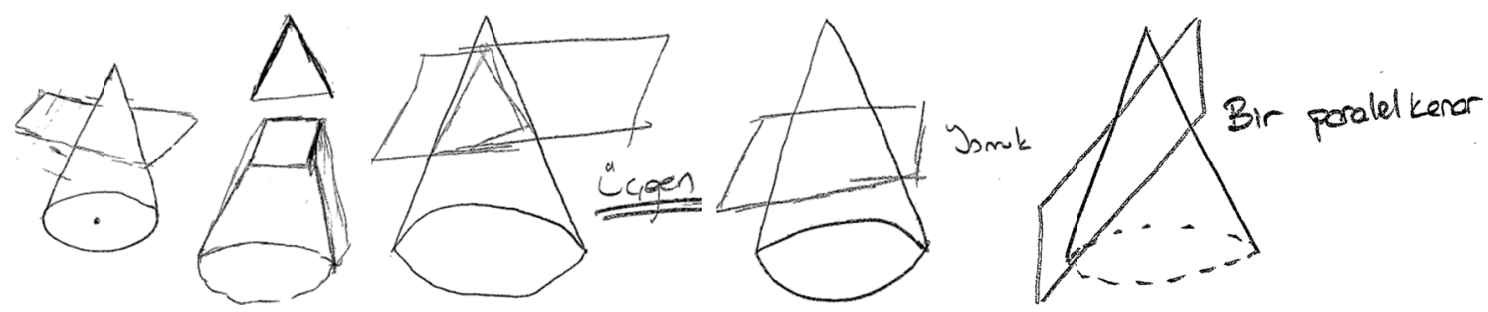

Figure 9. Examples of the given answers for the intersection of vertical cone and plane before using software

As seen in Figure 9, some prospective teachers gave answers such as circle, triangle, trapezoid, parallelogram, for the intersection of vertical cone and plane. Some prospective teachers defined the common area of the drawing of the objects in two dimensions as an intersection. This indicates that they have incomplete knowledge about intersections.

In the learning environment supported by Cabri 3D, the prospective teachers tried to identify the intersection surfaces by moving the shapes after they had drawn vertical cone and plane. The drawings made by the prospective teachers are presented in Figure 10.
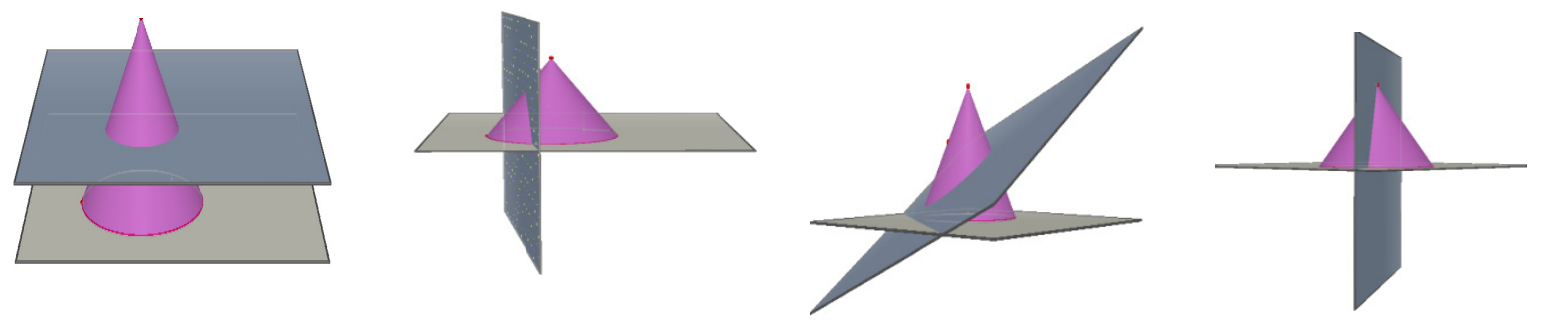

Figure 10. Examples of Cabri 3D drawings the intersection of vertical cone and plane

The answers of the prospective teachers related to the intersection of vertical cone and plane after using Cabri 3D dynamic software are presented in figure 11.
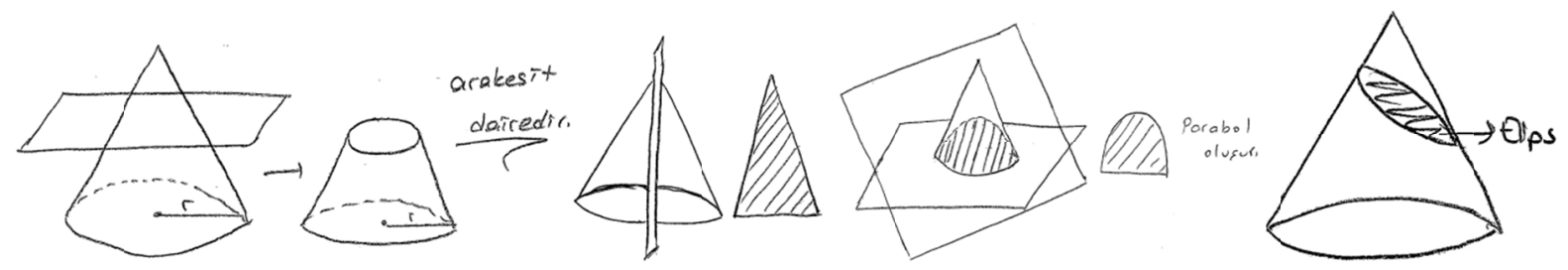

Figure 11. Examples of given answers for the intersection of vertical cylinder and plane after using software

As seen in Figure 11, drawings of the prospective teachers for the intersection of vertical cone and plane are more successful after using software. The use of the dynamic software helped the majority of the prospective teachers to realize also ellipse-shaped and parabola-shaped intersections. It was observed that after the implementation, the majority of the prospective teachers could notice intersections other than a parabola. It can be said that a parabola was less mentioned compared to the others, for the prospective teachers could not make enough experiments and observations. Some prospective teachers said that when the plane cut the cone perpendicular to the center of the cone, it would be a triangle, and some particularly mentioned that this triangle would be an isosceles triangle.

\subsection{The Findings Obtained from the Intersection of Cube and Plane}

The answers of the prospective teachers related to the intersection of cube and plane before and after using dynamic software are presented in figure 12. 


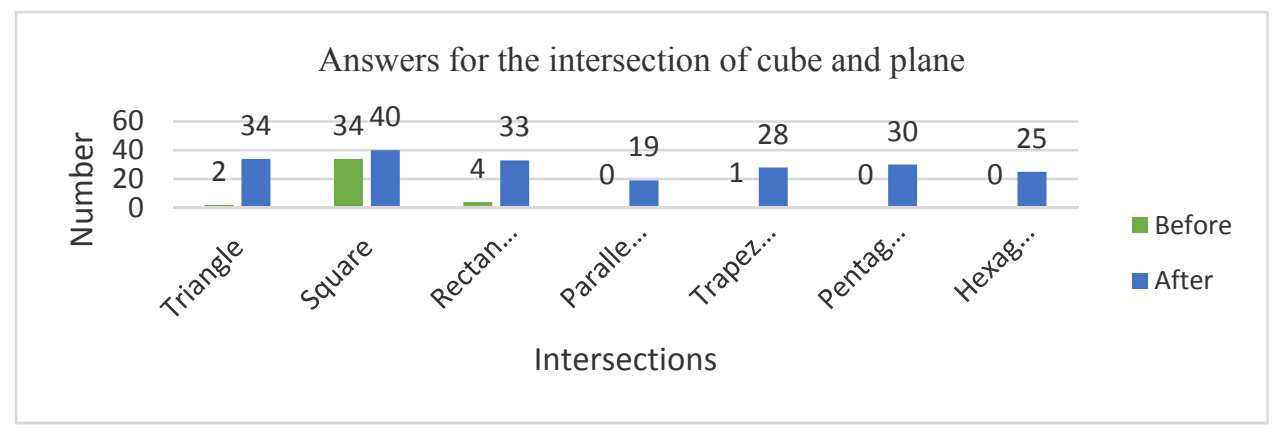

Figure 12. Answers for the intersection of cube and plane before using the software, and then.

As seen in Figure 12, the "square" answer was mentioned most for the intersection of cube and plane before using the dynamic software. Four prospective teachers gave "rectangle" and two prospective teachers gave a "square" answer. The explanation of some prospective teachers as "When a cube is cut by a plane, the shape of the base will always be obtained" attracted attention. Examples of Cabri 3D drawings of the prospective teachers are presented in figure 13 for the intersection of cube and plane after using software. These figures are snapshots taken from the dynamic drawings with Cabri 3D.
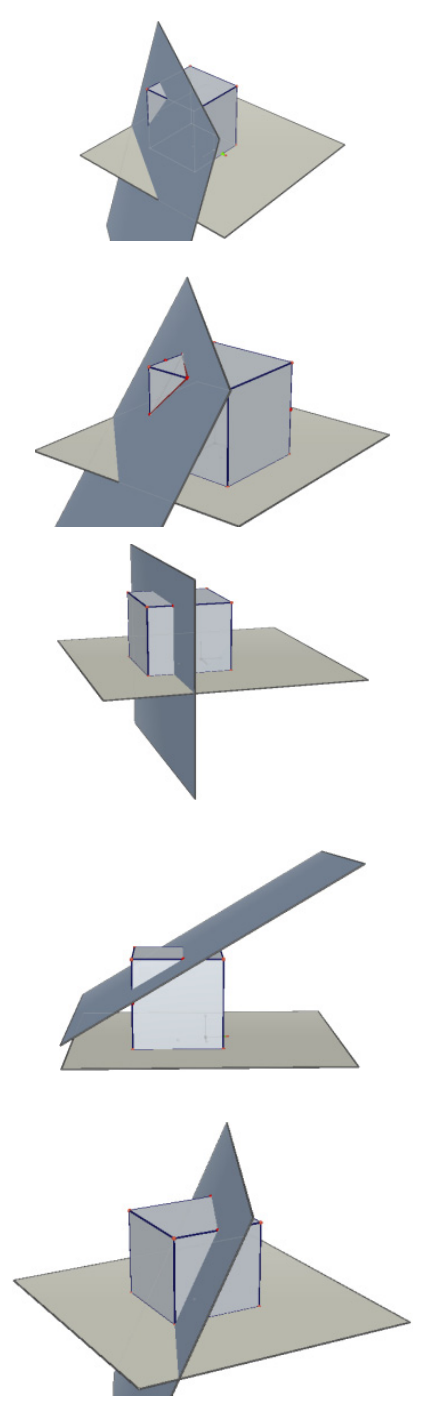
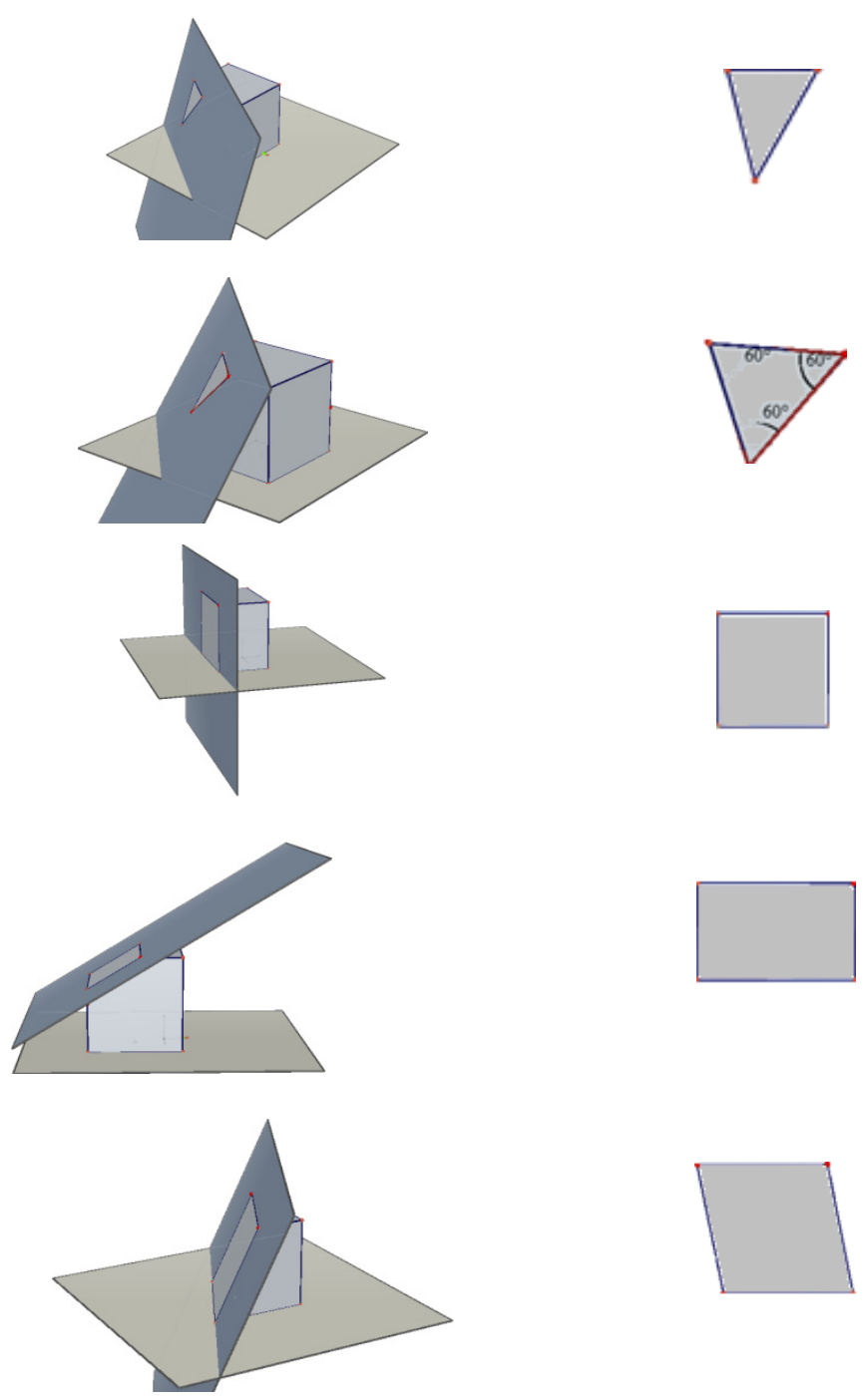

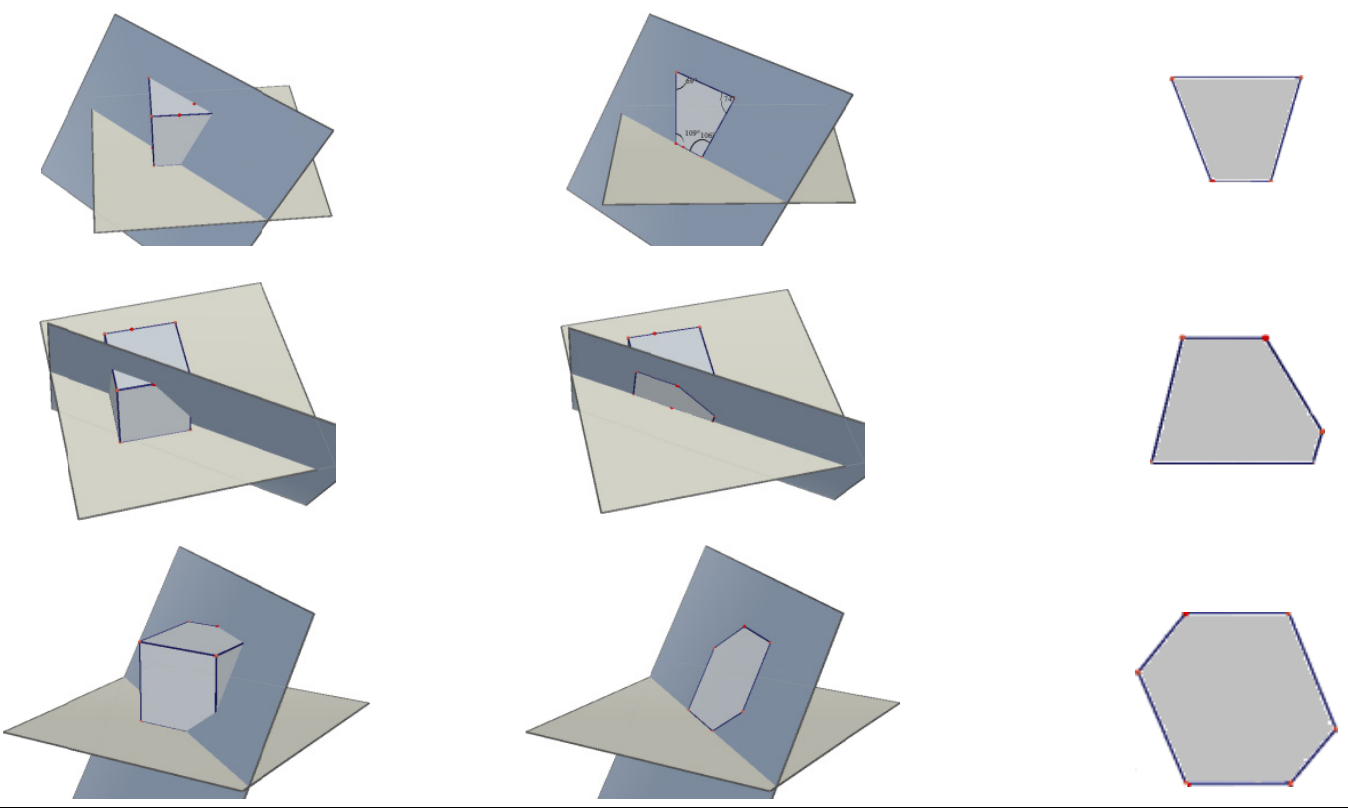

Figure 13. Examples of Cabri 3D drawings of the prospective teachers for the intersection of cube and plane.

It was found out that the majority of the prospective teachers could notice that other intersections were formed when the dynamic software was used. In the learning environment supported by Cabri 3D, the prospective teachers tried to identify the intersection surfaces by using the moving and cutting features after they had drawn cube and plane. The drawings made by the prospective teachers are presented in Figure 14.
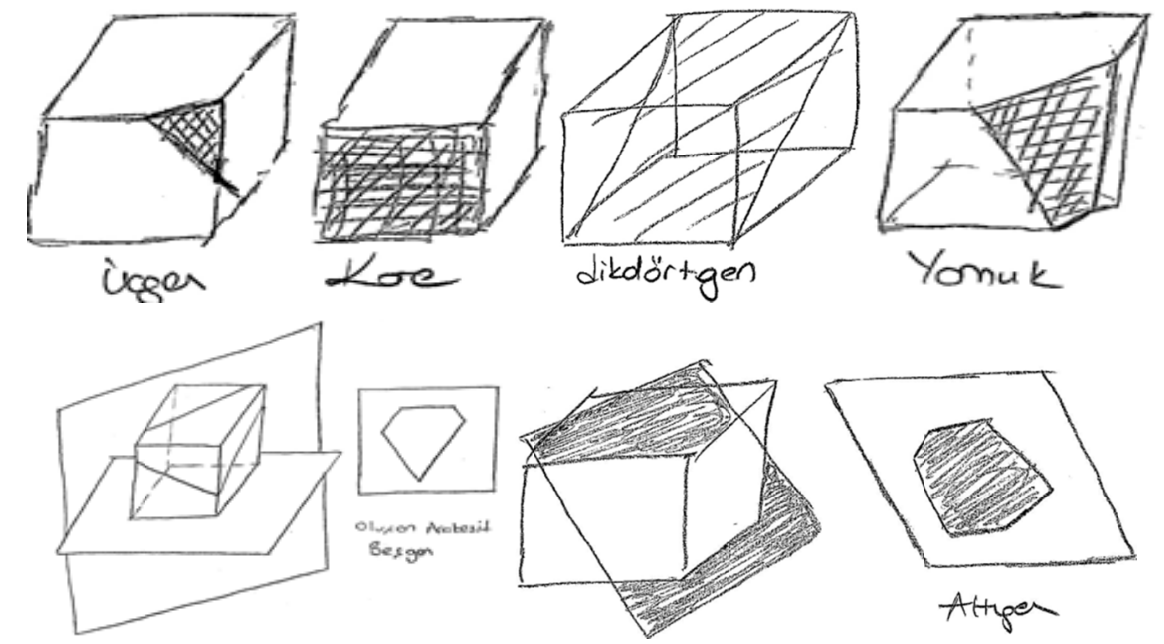

Figure 14. Examples of given answers for the intersection of cube and plane after using software

After the implementation, the majority of the prospective teachers mentioned that one of the intersections would be a triangle while some particularly named the intersections (equilateral triangle, isosceles triangle, scalene triangle).

\subsection{Findings Obtained from the Interviews}

In this section, the views of the prospective teachers about the implementation process were investigated and analyzed.

Similar considerations have been grouped and analyzed under specific themes. The sentences related to the themes were mentioned as they told so that the view of the prospective teachers tried to be reflected directly.

Software features: It was observed during the interviews that the prospective teachers emphasized the visualization, dynamics, cutting and recording features of the software. Interview sections related to that are given below.

Kenan: It was rather difficult for me to imagine the intersections and turn them around when I use pen and paper. Therefore, I had to make predictions and was not sure about them. Cabri $3 D$ has eliminated this difficulty. Thanks to the cutting feature of the Cabri 3D program, the intersection appears directly. There is no need to make predictions. 
Melda: We could see it/them/what? as three-dimensional on the computer and easily understand everything that we had not been able to see on the drawing made using a pen and paper. When I made drawing by hand, I drew an intersection surface for each question. However, I realized when using a computer that there were many other intersection surfaces that I had not been able to see before. Because planes are in different colors, shapes can be easily understood in Cabri 3D. I think it was very enjoyable.

Leyla: The drawings I made using a pen and paper prevented me from seeing three-dimensional. It was rather difficult to draw the situations left at the front or the back. If the shape is incorrect, then the answer will be incorrect, either. In addition, we cannot move the shape. This condition causes the illusion. Thus I could only think of simple cases. I found other intersections wrong. However, I could clearly see and understand the intersections by moving them with this program. The recording feature is also very good. Therefore, we do not need to re-draw. We can use repeatedly.

Changing views of the prospective teachers: It was observed that some changes had happened in the views of the prospective teachers after the implementation compared to those before the implementation. Some interview sections related that are given below.

Melda: I had found the intersection obtained when a cube had been cut by a plane as "square" as a result of my drawings made using a pen and paper. However, when I used the software, I realized that rectangular, trapezoid, pentagon, hexagon, parallelogram, triangle could be obtained. Beyond that, triangles can vary such as equilateral triangle, isosceles triangle and scalene triangle.

Leyla: When objects were cut with the plane on paper, only the situations in which it was cut horizontally and vertically came to my mind. Therefore, I could not see all intersections. However, we could see the other situations, for we could move the objects in the dynamic environment. When the plane is not vertical or horizontal to the surface, more different intersection surfaces can be obtained. I had found the intersection when a vertical cylinder had been cut by a plane as "triangle" by drawing using a pen and paper but when I used the software, I realized that rectangles and ellipse could be obtained as well. The subjects were embodied in the computer and settled better in my mind. I could obtain more intersections using a computer. I can say that Cabri $3 D$ convinced us about intersections.

Kenan: I could not predict that such various intersections would be obtained particularly from a cube. I never thought that a triangle would be obtained from a cube. I had the opportunity to examine the shapes from different angles. If I had been told about the intersections obtained with Cabri 3D, I would not be convinced, and it would not stay in my mind. This software has changed our way of thinking. I think computer-aided training is very good, I gained a different perspective.

Drawing simplicity: Some prospective teachers compared the drawings made on the computer with the ones made using a pen and paper. Interview sections about this are given below.

Leyla: Figures are difficult to create with paper and a pen. Everyone can not make drawings. I drew and erased many times. It was still no good. It is different in Cabri 3D. You can create the drawing in a very short time with just a few keys from the menu.

Time-saving: Leyla stated that she could easily draw the shapes that were difficult-to-draw and time-consuming, using the software, and she saved time.

Melda: Drawings took a lot of my time when I used a pen and paper. Additionally, I had to erase several times. We could create drawing with Cabri $3 D$ in a shorter time.

Usability: The interviewed prospective teachers shared the opinion that the use of the software in the course was beneficial. They stated that they could easily understand the topics that they had been unable to imagine thanks to the software. In addition, the interviewed prospective teachers stated that they found the software handy, and they would surely use it in their professional career. Interview sections about this are given below.

Melda: In my opinion, the fact that this software shows us the situations that are difficult to see helps us to imagine the situations to occur more easily. I think it is very useful for teaching geometry. I will use this software in my courses when I become a teacher.

Kenan: This program can be handled very comfortably in courses. I think its best feature is that it can show the shapes from different angles. If the shapes stand still, then there will be no difference from a two-dimensional plane. However, with this feature, if you show students the various intersections from different angles by moving the shapes around, then the students will not need to imagine. The resulting situation would be directly in front of them. For this, it is needed to know how to use the software. 
Leyla: This program is a very useful program for handling the course. I think it would be better for teachers to show the various situations that they consider necessary to teach and that the students have difficulty to realize, using the program, instead of drawing on the board or referencing the objects in the classroom or using the geometric objects. Physical materials are sometimes not enough to teach some subjects and to show some situations. In these situations, it would be useful to show objects from different angles and to teach the situations by changing them.

\section{Discussion}

In this study, it was aimed to examine the conclusions of the prospective teachers related to the intersections in the environments in which the dynamic software is used and not used. For this purpose, the prospective teachers were asked to state the intersections to be obtained when sphere, vertical cylinder, vertical cone, and cube are cut by a plane. Before the application, it was observed that the prospective teachers tried to show answers of the questions by using a pen and paper. Despite various attempts, their explanations related to the intersection surfaces remained limited. The majority of the prospective teachers created planes in a way that it was parallel to the base of the vertical cylinder, the vertical cone, and cube, or it passed through the center of the base center. This situation prevented them from seeing other intersections. Thus, the intersection of a cylinder and a plane was generally named as a circular region and rectangle; circular region and triangle for the intersection of vertical cone and plane. It was observed that some prospective teachers made false conclusions related to the intersection due to incorrect drawings. It was also observed that some prospective teachers considered the intersection regions of two objects drawn in a two-dimensional plane as an intersection. This indicates that their learning related to the intersection is inefficient. Only a few stated that their drawings were not good and wrote their predictions. After the implementation, it was observed that the prospective teachers were more successful in determining intersections and drawing more realistically. Moreover, some prospective teachers did not only determine the intersection surface, but also made explanations about the intersections for special conditions (for example: If a cube is cut from the middle point of the edges meeting at the corner of the cube by a plane, then the intersection will be an equilateral triangle). In general, the prospective teachers stated that they had gained experience with Cabri 3D, and their way of thinking had changed. Likewise, Couco and Goldenberg (1996) stated that with computer-assisted mathematics, students developed a unique way of thinking, gained an idea about the mathematical results, and at the same time, it enabled them to behave like a mathematician when reaching mathematical conclusions. In this study, the prospective teachers suggested that this software would be useful to handle the course, particularly for topics related to three-dimensional objects. Moreover, the prospective teachers were observed to be willing to use three-dimensional software when answering the questions related to intersections. Indeed, it was demonstrated in the studies conducted before that the use of dynamic geometry software in geometry courses helps the students to create a positive attitude towards these courses (Güven \& Karataş, 2003; Hazzan \& Goldenberg, 1997).

The prospective teachers experienced cutting objects in various shapes by moving the plane and observed the occurred intersection by moving the object when answering open-ended questions. Likewise, Arcavi and Hadas (2000) stated that dynamic geometry software contributed students by visualizing and experiencing, and they could make observations with these experiences. It can be said that in this study, the discovery and visualization offered by the software were applied successfully. Harel and Sowder (1998) demonstrated that when the moves and objects they saw on the computer screen were moved, it made a positive effect on their dynamic visualization skills that enabled them to make the same procedure more easily in their mind. Thus, they realized the mistakes they had made before using the software, and did not repeat them after using the software. Aşkar (1991) said that the best learning is that one realizes his mistakes, and it should not be forgotten that computers made this easier. Additionally, Laborde et al. (2006) concluded that the learning in the environments in which the dynamic geometry software was used, was not just a basic process in which the presented knowledge was taken, but it was a process in which they built and re-structured their geometry knowledge. In the light of this finding, it can be said that the individuals can restructure their own knowledge thanks to Cabri 3D dynamic software.

As a result of the findings obtained in this study, it was observed that the prospective teachers made incomplete and incorrect conclusions in finding the asked intersections, the conclusions did not base on the drawings but just predictions, and incorrect conclusions were made as a result of incorrect drawings. Besides, it was observed that when Cabri 3D software was used, the prospective teachers could easily determine the intersections thanks to the moving, locating the object with different angles and cutting features of the software. Likewise, Scher (1999) observed that proofing any theory or solving any problem using conventional pen and paper methods prevented the students from making discoveries, but the students understood better when the pen and paper process was supported with dynamic geometry software. In our schools, computer-supported learning environments should be created, pre-knowledge of the students should be checked and they should be enabled to experience new situations. It was observed that the use of the Cabri 3D software dynamic software as a supportive mean for the prospective teachers in the answering process of the 
problems related to the intersection of three-dimensional objects was useful. In the light of the obtained result, dynamic software that offers unique opportunities particularly in the three-dimensional studies should be used at each level.

\section{References}

Accascina, G., \& Rogora, E. (2006). Using cabri 3D diyagrams for teaching, International Journal for Technology in Mathematics Education, 13(1), 11-22.

Arcavi, A., \& Hadas, N. (2000). Computer mediated learning: An example of an approach. International Journal of Computers for Mathematical Learning, 5, 25-45. http://dx.doi.org/10.1023/A:1009841817245

Aşkar, P. (1991). Bilgisayar destekli öğretim ortamı, [Orientation in space: Computer-aided learning environment]. Paper presented at Quality Improvement and Researches in Education 1. Symposium, Istanbul.

Baki, A., Kösa, T., \& Karakuş, F. (2008). Uzay geometri öğretiminde 3D dinamik geometri yazılımı kullanımı: Öğretmen görüşleri, Paper presented at International Educational Technology Conference, Anadolu University, Eskişehir.

Demir, V. (2010). Cabri 3D dinamik geometri yazılımının, geometrik düşünme ve akademik başarı üzerine etkisi [The effect of cabri 3d dynamic geometry software on geometric thinking and academic achievement] (Unpublished master's thesis). Marmara Üniversity, Istanbul.

Eryiğit, P. (2010). Üç boyutlu dinamik geometri yazılımı kullanımının 12. sınıf öğrencilerinin akademik başarıları ve geometri dersine yönelik tutumlarına etkileri [The effect of utilizing the three dimensional dyinamic geometry software in geometry teaching on 12th grade students, their academic standings, their attitude towards geometry] (Unpublished master's thesis). Dokuz Eylül University, Izmir.

Gürbüz, R., \& Gülburnu M. (2013). 8. sınıf geometri öğretiminde kullanılan cabri 3D’nin kavramsal öğrenmeye etkisi. Turkish Journal of Computer and Mathematics Education, 4(3), 224-241.

Güven, B., \& Karataş, İ. (2003). Dinamik geometri yazılımı Cabri ile geometri öğrenme: Öğrenci görüşleri. The Turkish Online Journal of Educational Technology, 2(2), 67-78.

Harel, G., \& Sowder, L. (1998). Student proof schemes result from exploratory studies, In A. Schoenfeld, A., Kaput, J. \& Dubinsky, E. (Eds.) Research in Collegiate Mathematics III (pp. 234-282). Washington, D.C: American Mathematical Society.

Hazzan, O., \& Goldenberg, E. P. (1997). Students' understanding of the notion of function in dynamic geometry environments, International Journal of Computers for Mathematical Learning, 1(3), 263-291. http://dx.doi.org/10.1007/BF00182618

Karpuz, Y., Koparan, T., \& Güven, B. (2014). Using Figure and Concept Knowledge in Geometry. Turkish Journal of Computer and Mathematics Education, 5(2), 108-118. http://dx.doi.org/10.16949/turcomat.16832

Kösa, T. (2011). Ortaöğretim öğrencilerinin uzamsal becerilerinin incelenmesi [An investigation of secondary school students? spatial skills] (Unpublished doctoral dissertation). Karadeniz Technical University, Institute of Educational Sciences, Trabzon.

Kösa, T., \& Karakuş. F. (2010). Using dynamic geometry software cabri 3D for teaching analytic geometry. Procedia-Social and Behavioral Sciences, 2(2), 1385-1389. http://dx.doi.org/10.1016/j.sbspro.2010.03.204

Mistretta, R. M. (2000). Enhancing geometric reasoning. Adolescence, 35(138), 365-379.

Özen, D. (2009). İlköğretim 7. sınıf geometri öğretiminde dinamik geometri yazılımlarının öğrencilerin erişi düzeylerine etkisi ve öğrenci görüşlerinin değerlendirilmesi [The effect of dynamic geometry softwares on students? academic achievement level and the assessment of the students? opinions in geometry instruction at 7 th grade] (Unpublished master's thesis). Dokuz Eylül University, İzmir.

Scher, D. (1999). Problem solving and proof in the age of dynamic geometry, Micromath, 15 (1), 24-30. 